\title{
GROUP III METABOTROPIC GLUTAMATE RECEPTORS INHIBIT HYPERALGESIA IN ANIMAL MODELS OF INFLAMMATION AND NEUROPATHIC PAIN
}

Cyril Goudet $^{1,2}$, Eric Chapuy ${ }^{3}$, Abdelkrim Alloui ${ }^{3}$, Francine Acher ${ }^{4}$, Jean-Philippe Pin ${ }^{1,2}$ and Alain Eschalier ${ }^{3}$.

${ }^{1}$ Univ Montpellier I\&II, CNRS UMR5203, Institut de Génomique Fonctionnelle, 141 Rue de la Cardonille, F-34094 Montpellier Cedex 5, France.

${ }^{2}$ INSERM, U661, Montpellier, F-34094 France

${ }^{3}$ INSERM, UMR766, Pharmacologie Fondamentale et Clinique de la Douleur, Clermont-Ferrand, F-63000 France; Univ Clermont 1, Faculté de Médecine, Laboratoire de Pharmacologie Médicale, Clermont-Ferrand, F-63001 France; CHU Clermont-ferrand, Service de Pharmacologie, Clermont-Ferrand, F-63003 France.

${ }^{4}$ UMR8601-CNRS, Laboratoire de Chimie et Biochimie Pharmacologiques et Toxicologiques, Université Paris V, 45 rue des Saints-Pères, 75270 Paris 06, France

Manuscript : 22 pages

Figures : 6

Tables : 0

\section{Corresponding authors :}
Alain Eschalier, Pr
Cyril Goudet, Dr
Phone : +33 473.17.82.30
Phone : +33 467.14.29.33
Fax : +33 473.27.71.62
Fax : +33 467.54.24.32
Email : alain.eschalier@u-clermont1.fr
Email : cyril.goudet@,igf.cnrs.fr 


\section{ABSTRACT}

Glutamate plays a key role in modulation of nociceptive processing. This excitatory amino acid exerts its action through two distinct types of receptors, ionotropic and metabotropic glutamate receptors (mGluR). Eight mGluR have been identified and divided in three groups based on their sequence similarity, pharmacology and G-protein coupling. While the role of group I and II mGluRs is now well established, little is known about the part played by group III mGluRs in pain. In this work, we studied comparatively the involvement of spinal group III mGluR in modulation of acute, inflammatory and neuropathic pain. While intrathecal injection of ACPT-I, a selective group III mGluR agonist, failed to induce any change in vocalization thresholds of healthy animals submitted to mechanical or thermal stimuli, it dose-dependently inhibited the nociceptive behavior of rats submitted to the formalin test and the mechanical hyperalgesia associated with different animal models of inflammatory (carrageenan-treated and monoarthritic rats) or neuropathic pain (mononeuropathic and vincristine-treated rats). Similar effects were also observed following intrathecal injection of PHCCC, a positive allosteric modulator of mGlu4. Antihyperalgesia induced by ACPT-I was blocked either by LY341495, a non selective antagonist of mGluR, and by MAP4, a selective group III antagonist. This study provide new evidences supporting the role of spinal group III mGluRs in the modulation of pain perception in different pathological pain states of various etiologies but not in normal conditions. It more particularly highlights the specific involvement of mGlu4 in this process and may be a useful therapeutic approach to chronic pain treatment.

\section{KEYWORDS}

Glutamate, metabotropic glutamate receptor, hyperalgesia, neuropathic pain, inflammatory pain 


\section{INTRODUCTION}

Glutamate, released in the dorsal horn of the spinal cord from primary afferent fibers after noxious stimuli, activates two types of receptors: ionotropic (iGluRs) and metabotropic receptors (mGluRs). The iGluRs are ligand-gated ion channels responsible of fast synaptic transmission (Madden 2002). The mGluRs belong to the large family of G-protein coupled receptors and are responsible for the neuromodulatory activity of glutamate (Bockaert and Pin 1999; Pin et al. 2005). The mGluRs family is composed of 8 members divided in 3 groups, based on sequence homologies, coupling to second messengers systems and pharmacology. Group I mGluRs (mGlu1,5 receptors), primarily stimulate phosphoinositide hydrolysis whereas group II (mGlu2,3) and group III (mGlu4,6,7 and 8) are negatively coupled to adenylate cyclase. The mGluRs are widely distributed throughout the central nervous system and play important roles in regulating cell excitability and synaptic transmission. One of the primary functions of group II and III mGluRs is a presynaptic autoreceptor role involved in reducing glutamate transmission at glutamatergic synapses. They also serve as heteroreceptors involved in reducing GABA release at inhibitory synapses. Finally, postsynaptically localized mGluRs (primarily of group I) often play an important role in regulating neuronal excitability and in regulating currents through ionotropic glutamate receptors.

The mGluRs regulate nociceptive processes at different levels of the nervous system and are critically involved in central sensitization which is associated with chronic pain (Woolf and Salter 2000). Thus, these receptors appear as interesting targets for the development of new analgesics. Present data in literature indicate that blocking group I mGluRs or activating group II or III mGluRs produce antinociceptive effects (Neugebauer 2001; 2002; Varney and Gereau 2002; Neugebauer 2007). However, due to the lack of specific pharmacology, assessing the specific roles of the different mGluRs in pain is difficult (Neugebauer 2007). It is particularly the case for group III mGluRs. Indeed, while group I and II involvement in pain is well documented, the specific role of group III mGluRs is still poorly understood. However, group III mGluRs are especially abundant all along the nociceptive pathways and particularly in the terminals of primary afferent fibers in the dorsal horn of the spinal cord, a key localization for the regulation of ascending informations (Li et al. 1997; Azkue et al. 2001).

This work is focused on the less studied group III mGluRs in pain modulation. We have comparatively studied the involvement of spinal group III mGluRs both in acute and various chronic pain models in rats, using ACPT-I, a selective group III mGluR agonist (Acher et al. 1997), and PHCCC, a selective mGlu4 positive allosteric modulator (Maj et al. 2003; Marino et al. 2003) following intrathecal injection. We show here that ACPT-I or PHCCC reduced mechanical 
hyperalgesia in inflammatory and neuropathic pain models without affecting behavioral reactions to painful stimuli in healthy animals. This study clearly demonstrates that activation of spinal group III mGluRs and mGlu4 in particular inhibits the transmission of pain in chronic pain models of various etiologies but not in normal conditions.

\section{MATERIALS AND METHODS}

\subsection{Cell culture, transfection and functional assay}

HEK293 cells were cultured in Dulbecco's modified Eagle's medium supplemented with 10\% FCS and antibiotics (Penicillin and Streptomycin, $100 \mathrm{U} / \mathrm{ml}$ final). Culture medium, fœtal calf serum (FCS) and other products used for cell culture were purchased from GIBCO-BRL-Life Technologies, Inc. (Cergy Pontoise, France). Glutamate-pyruvate transaminase (GPT) was purchased from Roche (Basel, Switzerland).

Cells were transiently transfected with rat clones of group I (mGlu1,5), group II (mGlu2,3) or group-III mGlu receptors by electroporation as described elsewhere (Brabet et al. 1998). To avoid any influence of glutamate released by the cells in the assay medium, the high affinity glutamate transporter EAAC1 was also co-transfected with the receptor. Since group-II and groupIII mGluRs are naturally couple to the adenylyl-cyclase pathway through Gi/o-protein activation, these receptors were co-transfected with a chimeric G-protein which is recognized by these receptors but couples to the phospholipase-C pathway and thus lead to inositol phosphate (IP) production following receptor activation (Gomeza et al. 1996). Receptor activity was then determined by IP measurement.

Inositol phosphate accumulation experiments were performed in 96-well microplates as already described (Goudet et al. 2004). Briefly, following transfection, cells were incubated overnight with ${ }^{3} \mathrm{H}$-myoinositol (16 Ci/mmol; Amersham, Buckinghamshire, UK). The next day, cell medium was removed, cells were rinsed and ambient glutamate degraded by incubation in presence of GPT. Cells were stimulated by ACPT-I (Tocris Cookson Ltd., Bristol, UK) for 30 minutes then the medium was removed and cells incubated with cold $0.1 \mathrm{M}$ formic acid which induced cell lysis. Then ${ }^{3} \mathrm{H}-\mathrm{IP}$ produced following receptor stimulation were recovered by ion exchange chromatography using a Dowex resin (Biorad). IP kept by the resin were then eluted by a solution highly concentrated in formate $(4 \mathrm{M})$, collected in a 96-wells sample plate, mixed with liquid 
scintillator (Perkin Elmer). The radioactivity remaining in the membranes is used to normalize the IP produced. Membranes were solubilized with a solution of $\mathrm{NaCl}(0.1 \mathrm{M})$ containing $10 \%$ of Triton X100 (Sigma), the resulting solution was then collected in a 96-well sample plate and mixed with liquid scintillator. Radioactivity was counted using a Wallac 1450 Microbeta stintillation and luminescence counter (Perkin Elmer). Results are expressed as the ratio between IP and the total radioactivity corresponding to IP plus membrane. All points are realized in triplicate.

The dose-response curves were fitted using the GraphPad Prism program and the following equation: $\mathrm{y}=\left[\left(\mathrm{y}_{\max }-\mathrm{y}_{\min }\right) /\left(1+\left(\mathrm{x} / \mathrm{EC}_{50}\right)^{\mathrm{n}}\right)\right]+\mathrm{y}_{\min }$ where $\mathrm{EC}_{50}$ is the concentration of the compound necessary to obtain the half maximal effect and $\mathrm{n}$ is the Hill coefficient.

\subsection{Uptake experiments}

Glutamate uptake experiments were performed as already described (Pin et al. 1984). Briefly, whole brains from male rats were homogenized in ice cold sucrose $(0.32 \mathrm{M})$ and centrifuged at $1000 \mathrm{~g}$ for 10 minutes at $4^{\circ} \mathrm{C}$. The supernatant was then centrifuged at $17.000 \mathrm{~g}$ during 20 minutes. The resulting pellet was lysed in cold water for 45 minutes. Membranes were then centrifuged at 20.000 g during 35 minutes, washed and resuspended in 50mM Tris-citrate buffer (pH7.4). ${ }^{3} \mathrm{H}$-glutamate (50 Ci/mmole) was purchased from American Radiolabeled Chemicals, Inc. (St Louis, U.S.A.). Uptake of ${ }^{3} \mathrm{H}$-glutamate was measured by incubating $100 \mu \mathrm{L}$ of membrane suspension, $50 \mu \mathrm{L}$ of $3 \mathrm{H}$-glutamate (final concentration of $100 \mathrm{nM}$ ) and $50 \mu \mathrm{L}$ of buffer containing or not unlabeled displacing substances at various concentrations (L-glutamate, L-AP4 or ACPT-I), in presence of 2.5 $\mathrm{mM} \mathrm{CaCl} 2$. The final protein concentration was $2 \mathrm{mg} / \mathrm{mL}$. After 10 minutes, the incubation was stopped by addition of $3 \mathrm{~mL}$ of cold buffer and filtered on filter paper (FP205, Whatman GF/C). Filter was washed twice with $3 \mathrm{~mL}$ buffer and counted in a Tricarb liquid scintillation counter (Packard). Specific uptake was determined by substracting the non specific binding in presence of $250 \mu \mathrm{M}$ unlabeled glutamate from the total binding.

\subsection{Animals}

Adult male Sprague-Dawley rats weighting 175-200 g were purchased from Charles River. Animals were housed under controlled environmental conditions $\left(22^{\circ} \mathrm{C} ; 55 \%\right.$ humidity $)$ and kept under a 12/12h light/dark cycle, with food and water ad libitum for a week prior to start the experiments in order to acclimatize. Animal care and experiments were carried out in accordance with the Committee for Research and Ethical Issues of the IASP (Zimmermann 1983). 


\subsection{Behavioral testing}

\subsubsection{Paw pressure test.}

The animals were submitted to the paw pressure test previously described by Randall and Selitto (1957). Nociceptive thresholds, expressed in grams (g), were measured with a Ugo Basile analgesimeter (Apelex, tip diameter of the probe: $1 \mathrm{~mm}$, weight: $30 \mathrm{~g}$ ) by applying an increasing pressure to the right hind paw of rats until a squeak (vocalization threshold) was obtained (cut-off was $750 \mathrm{~g}$ ). The treatments were done after the measurement of two consecutive stable vocalization threshold values and their effects were assessed 15, 30, 45, 60, 90 and 120 min after.

\subsubsection{Formalin test.}

Following acclimatization for $20 \mathrm{~min}$ in the test chamber, rats received $50 \mu \mathrm{L}$ of $2.5 \%$ formalin injected subcutaneously (s.c.) into the plantar surface of the hind paw. They were then replaced in the Plexiglas box. Biting and licking of the injected paw were monitored by measuring the total duration of the response in seconds during the two peaks of the typical biphasic pain behavior previously described (Wheeler-Aceto et al. 1990; Oyama et al. 1996). The spontaneous aversive response corresponding to the early phase was assessed during the first $5 \mathrm{~min}$. The second peak of aversive behavior was observed from 20 to $40 \mathrm{~min}$ after formalin administration. Drug treatments (ACPT-I, saline i.t.) were performed $15 \mathrm{~min}$ before formalin injection.

\subsubsection{Tail immersion test.}

The tail of the rat was immersed in a hot water bath maintained at $46^{\circ} \mathrm{C}$. The time latency for tail withdrawal was then determined and a cut-off time of $30 \mathrm{~s}$ was applied to avoid injury.

\subsection{Persistent pain models: Inflammatory pain models}

\subsubsection{Carrageenan-induced mechanical hyperalgesia.}

Thresholds to mechanically induced vocalization were assessed with rats presenting an hyperalgesia elicited by a subcutaneous injection of $\lambda$-carrageenan $(200 \mu \mathrm{g})$ into the right hind paw $(10 \mu \mathrm{L})$. Four hours later, vocalization thresholds were significantly decreased from $218 \pm 30 \mathrm{~g}$ to $117 \pm$ $23 \mathrm{~g}$.

\subsubsection{Model of monoarthritis.}

This model was previously described by Butler et al, 1992 (Butler et al. 1992). Briefly, on day 0, monoarthritis was induced by a single intra-articular injection of $0.05 \mathrm{~mL}$ of complete Freund's adjuvant (CFA) performed under brief 5\% isoflurane anesthesia into the right ankle. Before 
injection and 14 days after, rats were submitted to the paw pressure test by applying an increasing pressure to ankle until a vocalization was obtained (276 \pm 35 and $135 \pm 29 \mathrm{~g}$, respectively).

\subsection{Persistent pain models: Neuropathic pain models.}

\subsubsection{Chronic Constriction Injury (CCI) model.}

Unilateral peripheral mononeuropathy was induced according to the method described by Bennett and Xie (Bennett and Xie 1988). Briefly, after determining vocalization thresholds, rats were anesthetized with sodium pentobarbital (50 mg/kg i.p.) and four chromic gut (5-0) ligatures were tied loosely (with about 1-mm spacing) around the right common sciatic nerve. The nerve was constricted to a barely discernible degree, so that circulation through the epineurial vasculature was not interrupted. Only animals presenting a decrease $\geq 15 \%$ of the presurgery value of vocalization threshold were selected, i.e. $90 \%$ of ligated animals (pre-surgery value: $269 \pm 30$ g, pre-drug value: $179 \pm 25 \mathrm{~g})$.

\subsubsection{Vincristine-induced mechanical hyperalgesia.}

This model of neuropathic pain was previously described by Authier et al, 2003 (Authier et al. 2003). Briefly, five intravenous injections of $150 \mu \mathrm{g} / \mathrm{kg}$ of vincristine (Oncovin ${ }^{\circledR}$, Elly Lilly) were performed every 2 days until a cumulative dose of $750 \mu \mathrm{g} / \mathrm{kg}$ was reached. Preliminary vocalization thresholds to paw pressure (the mean of two consecutive stable values which do not differ more than $10 \%$ ) were determined before the beginning of vincristine treatment (control pre-injury value: $296 \pm 32 \mathrm{~g}$ ). Only animals with a decrease $\geq 15 \%$ of the presurgery value of vocalization threshold were selected, i.e. $73 \%$ of injected animals. Hyperalgesia was observed 14 days after the beginning of vincristine treatment (control pre-drug value: $178 \pm 28 \mathrm{~g}$ ).

\subsection{Experimental procedure and drugs.}

\subsubsection{Treatment protocol.}

For all experiments, treatments, always injected intrathecally, were randomized and administered according to the method of blocks in order to assess the effect of the different treatments at the same time interval to avoid uncontrolled influences (one block includes a number of animals corresponding to the number of the different treatments administered ; all animals in a same block are tested in the same short laps of time; the number of blocks corresponds to the number of animals per treatment). Different animals were used for each experiments $(n=6-10$ per treatment, according 
to the experiments) performed in a blinded manner in a quiet room and animal behaviors were observed by a single experimenter.

\subsubsection{Intrathecal injections.}

Intrathecal injections were performed, under isoflurane anesthesia (4\% induction, 2\% maintenance), as previously described (Mestre et al. 1994). Briefly, the anaesthetized rat was held in one hand by the pelvic girdle and a 25 -gaugeX1-inch needle connected to a $25 \mu \mathrm{L}$ Hamilton syringe was inserted into the subarachnoidal space between lumbar vertebrae L5 and L6, until a tail flick was elicited. The syringe was held in position for few seconds after the injection of a volume of $10 \mu \mathrm{L} / \mathrm{rat}$.

\subsubsection{Drugs.}

For intrathecal injections, ACPT-I, LY341495, MAP4 (Tocris Cookson Ltd, Bristol, UK) and PHCCC (Ascent scientific, Weston-Super-Mare, UK) were dissolved in saline $(0.9 \% \mathrm{NaCl}, \mathrm{B}$. Braun, Melsungen, Germany). All solutions were prepared immediately prior to injection.

\subsection{Expression of results and statistical analysis}

The cumulative biting and licking time of each phase of response was generated for each rat in the formalin test. The data (mean \pm SEM) are expressed as time (in s) spent in biting and licking of the hind paw that received formalin. One-way analysis of variance (ANOVA) was performed and followed by a Student-Newman-Keuls' test when appropriate. A $\mathrm{p}<0.05$ was taken as statistically significant.

For the mechanical pain test, the results are expressed as vocalization thresholds (in grams). To investigate global effects, areas under the time-course curves (AUCs, g.min) of the antihyperalgesic effects were calculated from individual scores at each time, using the trapezoidal method. Data were analyzed by a two-way ANOVA followed, when the F value was significant, by a Dunnett's test, when the time-course of the effects was studied. One-way ANOVA followed by a Student-Newman-Keuls' test was used to analyze the effect of the different treatments determined by the AUCs. The level of statistical significance was set at $\mathrm{p}<0.05$.

\section{RESULTS}

\subsection{ACPT-I is a selective group III mGluR agonist}


Due to the high structural similarity between the different members of each group of the mGluR family, only group selective agonists and antagonists are available. Indeed, to date, there is no selective agonist of a given subtype of group III mGluRs. However, few group III selective agonists exist (see (Pin and Acher 2002) for a review), the best representatives being L-AP4 and ACPT-I.

To perform the present study we have chosen ACPT-I, a cyclic analog of glutamate, that we previously reported to activate mGlu4, but was without effect on mGlu1 and mGlu2 (Acher et al. 1997). Here we further characterize the effect of this glutamate analog on most mGluRs. In HEK293 cells, ACPT-I selectively and dose-dependently activates all group-III receptors expressed and is devoid of non-specific agonist activity at $100 \mu \mathrm{M}$ on the other members of the mGluR family (Fig.1A and 1B). From dose-response curves, the half-maximal concentration of ACPT-I necessary to yield $50 \%$ of the maximal activity (EC50) of group-III receptors can be calculated. The mean EC50 value of ACPT-I on mGlu4, mGlu6, mGlu7 and mGlu8 receptors are $1.0 \pm 0.2 \mu \mathrm{M}(\mathrm{n}=6)$, $13.0 \pm 4.6 \mu \mathrm{M}(\mathrm{n}=4), 2.0 \pm 0.1 \mathrm{mM}(\mathrm{n}=3)$ and $6.3 \pm 0.6 \mu \mathrm{M}(\mathrm{n}=3)$, respectively. ACPT-I is also devoid of non specific antagonist activity at mGlu1, mGlu2 and mGlu5 receptors (data not shown). Recently, several reports also support a selective action of ACPT-I on group-III mGluRs in vivo (Klak et al. 2007; Konieczny et al. 2007; Lopez et al. 2007).

Although L-AP4 is commonly used as a group III agonist, this compound also acts at the Cldependent glutamate transport (Pin et al; 1984), likely the $\mathrm{x}_{\mathrm{c}^{-}}$transport system (Patel et al. 2004). Of interest, whereas L-AP4 inhibits Cl-dependent glutamate transport, ACPT-I was far less active at this system (Fig.1C). At $100 \mu \mathrm{M}$, ACPT-I inhibited the chloride-dependent, sodium-independent transport of L- ${ }^{3} \mathrm{H}-$ Glutamate by $13.8 \pm 1.4 \%(\mathrm{n}=3)$ whereas L-AP4 $(100 \mu \mathrm{M})$ inhibited the uptake by $70.4 \pm 17.4 \%(n=3)$.

\subsection{Antinociceptive effect of ACPT-I in healthy animals}

\subsubsection{Mechanical stimulation}

Intrathecal administration of ACPT-I (20, 40 or $80 \mu \mathrm{g} / \mathrm{rat})$ failed to induce any antinociception in healthy rats submitted to the paw pressure test, in contrast to morphine (10 $\mu \mathrm{g} / \mathrm{rat})$ injected in the same conditions which significantly increased the vocalization threshold (Fig.2A).

\subsubsection{Thermal stimulation}


The latency of tail withdrawal of healthy rats submitted to tail immersion test was not modified following the intrathecal administration of ACPT-I (20, 40 or $80 \mu \mathrm{g} / \mathrm{rat})$ while morphine $(10 \mu \mathrm{g} / \mathrm{rat})$ injected in the same conditions significantly increased the delay of withdrawal (Fig.2B).

\subsubsection{Chemical stimulation: formalin test}

As can be seen in Fig.2C, ACPT-I significantly and dose-dependently decreased the biting/licking behavior induced by formalin during both phases of the test. The early phase was significantly reduced by doses equal or higher than $2 \mu \mathrm{g} / \mathrm{rat}$ while the late phase was significantly decreased by doses equal or higher than $10 \mu \mathrm{g} / \mathrm{rat}$. The maximal dose of ACPT-I used ( $80 \mu \mathrm{g} / \mathrm{rat}$ ) induced a mean decrease of $48 \pm 6 \%(n=6)$ and $63 \pm 10 \%(n=6)$ of the first and second phase scores, respectively. This efficacy was not statistically different from that of morphine $(10 \mu \mathrm{g} / \mathrm{rat})$.

\subsection{ACPT-I inhibited mechanical hyperalgesia in inflammatory pain models}

\subsubsection{Antihyperalgesic effect of ACPT-I in carrageenan-treated rats}

Intrathecal administration of ACPT-I significantly and dose-dependently increased the vocalization threshold of carrageenin-treated rats submitted to the paw pressure test (Fig.3A). Significant difference in time-course of the vocalization threshold started at $20 \mu \mathrm{g} / \mathrm{rat}$ and was clearly increased after the administration of 40 and $80 \mu \mathrm{g} /$ rat of ACPT-I. The maximal increase was observed 30 minutes after the injection of $80 \mu \mathrm{g} /$ rat of ACPT-I (mean value of $+51 \pm 9 \%(\mathrm{n}=8)$ as compared to the pre-drug value) and the measured vocalization threshold was not statistically different from the corresponding pre-carrageenan mean vocalization threshold $(218 \pm 7(\mathrm{n}=8)$ and $208 \pm 16 \mathrm{~g}(\mathrm{n}=8)$, respectively) suggesting a reversion of mechanical hyperalgesia by ACPT-I. This dose-dependent effect was confirmed when AUC were calculated (Fig. 3A). In the same conditions, morphine (10 $\mu \mathrm{g} / \mathrm{rat}$ ) administered to carrageenan-treated rats increased the measured vocalization thresholds higher than the corresponding pre-carrageenan vocalization threshold (mean values of $463 \pm 48 \mathrm{~g}$ $(\mathrm{n}=8)$ and $229 \pm 21 \mathrm{~g}(\mathrm{n}=8)$, respectively)(Fig. 3A).

\subsubsection{Antihyperalgesic effect of ACPT-I in monoarthritic rats}

Two weeks after CFA injection, the mechanical hyperalgesia assessed by the paw pressure test was partially reversed by ACPT-I injected intrathecally (Fig3B). The vocalization thresholds in rats treated with 40 or $80 \mu \mathrm{g} / \mathrm{rat}$ of ACPT-I significantly and dose-dependently increased, with a mean 
maximal increase of $70 \pm 16 \%(\mathrm{n}=8)$ observed 30 minutes after treatment $(80 \mu \mathrm{g} / \mathrm{rat})$ as compared to pre-treatment value (from $139 \pm 10 \mathrm{~g}(\mathrm{n}=8)$ to $227 \pm 18 \mathrm{~g}(\mathrm{n}=8), 30$ minutes after intrathecal injection of ACPT-I at $80 \mu \mathrm{g} / \mathrm{rat}$ ). This effect lasted for 80 minutes after the injection of the highest dose. In the same conditions, morphine $(10 \mu \mathrm{g} / \mathrm{rat})$ increased the measured vocalization thresholds higher than the corresponding pre-injury mean vocalization threshold $(319 \pm 45 \mathrm{~g}(\mathrm{n}=8)$ and $276 \pm$ $35 \mathrm{~g}(\mathrm{n}=8)$, respectively).

\subsection{Influence of ACPT-I in neuropathic pain models.}

\subsubsection{Antihyperalgesic effect of ACPT-I in mononeuropathic rats (CCI model).}

The vocalization thresholds of mononeuropathic rats submitted to the paw pressure test were significantly and dose-dependently increased following intrathecal administration of ACPT-I (Fig.4A). Following the administration of 40 and $80 \mu \mathrm{g} /$ rat of ACPT-I, vocalization threshold timecourse was significantly shifted upward, while scores of animals treated with $20 \mu \mathrm{g} / \mathrm{rat}$ of agonist remained equivalent to those of saline-treated animals. The effect due to $80 \mu \mathrm{g} / \mathrm{rat}$ was plateauing from 15 to $45 \mathrm{~min}$ after injection with a mean maximal increase of $76 \pm 13 \%(n=7)$ as compared to the pre-drug value. The reached score (mean value: $310 \pm 23 \mathrm{~g}(\mathrm{n}=7), 30$ minutes after intrathecal injection) was not statistically different from pre-injury mean value $(283 \pm 22 \mathrm{~g}, \mathrm{n}=7)$ suggesting a complete reversion of mechanical hyperalgesia by ACPT-I.

\subsubsection{Antihyperalgesic effect of ACPT-I in vincristine-treated rats}

Intrathecal injection of ACPT-I significantly and dose-dependently increased the vocalization threshold of vincristine-treated rats submitted to the paw pressure test (Fig.4B). Vocalization threshold time-course was significantly different following the administration of 40 and $80 \mu \mathrm{g} / \mathrm{rat}$ of ACPT-I as compared to saline-treated animals. The maximal increase was observed 45 minutes after the injection of the $80 \mu \mathrm{g} / \mathrm{rat}$ dose (mean increase value of $+56 \pm 17 \%(\mathrm{n}=8)$ as compared to the pre-drug value), reached threshold being not statistically different from corresponding previncristine value $(270 \pm 36 \mathrm{~g}(\mathrm{n}=8)$ and $296 \pm 32 \mathrm{~g}(\mathrm{n}=8)$, respectively).

\subsection{Effect of ACPT-I was blocked by mGluRs antagonists.}

\subsubsection{Blockade by a non selective mGluR antagonist, LY341495.}


In order to verify that ACPT-I antihyperalgesic effect was mediated through its action on mGlu receptors, we used a classical non selective mGluRs antagonist, LY341495 (Pin and Acher 2002), co-injected at different doses $(62.5,125$ and $250 \mu \mathrm{g} / \mathrm{rat})$ with ACPT-I $(80 \mu \mathrm{g} / \mathrm{rat})$ or saline in carrageenan-treated rats. LY341495 had no effect by itself. The vocalization thresholds of rats treated with LY341495 and saline did not differ significantly from the thresholds measured in rats treated with saline only (data not shown). However, as can be seen in Fig.5A, increasing doses of LY341495 progressively reduced and almost completely abolished, for the highest dose (250 $\mu \mathrm{g} / \mathrm{rat}$ ) (mean inhibition: $97 \pm 7 \%, \mathrm{n}=7$ ), ACPT-I-induced antihyperalgesia.

\subsubsection{Blockade by a selective group III mGluR antagonist, MAP4.}

Then, to confirm that ACPT-I antihyperalgesic effect was induced by group-III mGlu receptor activation, we used a selective group-III mGluRs antagonist MAP4 (Pin and Acher 2002), coinjected at different doses $(25,50$ and $100 \mu \mathrm{g} / \mathrm{rat})$ with ACPT-I $(80 \mu \mathrm{g} / \mathrm{rat})$ or saline in a model of inflammatory pain, carrageenan-treated rats. Figure 5B displays the dose-dependent blockade of ACPT-I-induced antihyperalgesia by MAP4. At higher dose, MAP4 almost completely abolished the effect of $80 \mu \mathrm{g}$ of ACPT-I, inducing a mean maximal decrease in the antihyperalgesic effect of $81 \pm 11 \%(\mathrm{n}=8)$. In parallel, MAP4 displayed no intrinsic activity, the vocalization threshold of MAP4 + saline treated rats being no significantly different of rats treated only with saline (data not shown).

Similar experiments with ACPT-I versus ACPT-I + MAP4 were conducted in the CCI model (Fig.5C). In mononeuropathic rats, vocalization thresholds of rats treated with MAP4 (50 $\mu \mathrm{g} / \mathrm{rat})$ and saline or saline only, injected intrathecally, were not statistically different, illustrating that MAP4 had no effect by itself. However, antihyperalgesic effect of ACPT-I ( $80 \mu \mathrm{g} / \mathrm{rat})$ was almost completely abolished ( $84 \pm 6 \%, \mathrm{n}=9)$ when co-injected with MAP4 (50 $\mu \mathrm{g} / \mathrm{rat})$.

\subsection{PHCCC inhibited mechanical hyperalgesia in both inflammatory and neuropathic pain models.}

In order to identify which receptor among the three group III mGluRs expressed in the spinal cord is involved in the ACPT-I effect, we performed experiments with the only group III subtype selective compound available today: PHCCC (Maj et al. 2003; Marino et al. 2003). This compound is a positive allosteric modulator of mGlu4, devoid of activity at the other group III mGluRs.

When given via intrathecal route in healthy rats, PHCCC (10, 20 and $40 \mu \mathrm{g} / \mathrm{rat})$ did not affect the vocalization threshold of animals submitted to the paw pressure test (Fig.6A). 
However, intrathecal administration of PHCCC significantly and dose-dependently increased the vocalization threshold of carrageenan-treated rats submitted to the paw pressure test (Fig.6B). This dose-dependent effect was confirmed when AUC were calculated (Fig.6A, right panel). The maximal increase (mean value $+84 \pm 14 \%(n=8)$ ) was observed 30 minutes after the injection of $40 \mu \mathrm{g}$ PHCCC per rat (from a pre-drug mean threshold value of $123 \pm 7 \mathrm{~g}(\mathrm{n}=8)$ to $240 \pm 19 \mathrm{~g}(\mathrm{n}=8))$ and the measured vocalization thresholds was not statistically different from the corresponding pre-carrageenan mean vocalization threshold $(223 \pm 7 \mathrm{~g}(\mathrm{n}=8))$ suggesting a reversion of mechanical hyperalgesia by PHCCC.

In mononeuropathic rats, PHCCC also significantly increased the vocalization threshold in the paw pressure test (Fig.6B). The effect was again dose-dependant with a maximum reached 15 minutes after injection of $40 \mu \mathrm{g}$ (mean value $+60 \pm 8 \%(\mathrm{n}=8)$ ). and the obtained threshold was not statistically different from that measured before surgery (mean vocalization threshold measured before surgery: $283 \pm 5 \mathrm{~g}$, before injection: $176 \pm 7 \mathrm{~g}$, after injection: $270 \pm 13 \mathrm{~g},(\mathrm{n}=10)$ ).

These data show that like ACPT-I, the mGlu4 selective positive modulator PHCCC reverses the hyperalgesia observed in inflammatory and mononeuropathic animal models, but does not lead to full analgesia.

\section{DISCUSSION}

Using healthy animals, neuropathic pain models from different etiologies (post-traumatic or iatrogenic) and models of more or less prolonged inflammatory pain, the present study gives an extended picture of the putative analgesic effect resulting from spinal group-III mGluRs activation. This study further demonstrated that the activation of these receptors by intrathecal administration of a selective agonist or positive allosteric modulator inhibits the mechanical hypersensitivity associated with the different conditions of intense or persistent pain while reactions to acute noxious stimuli remain unchanged. Particularly, it highlights the role of mGlu4 in this process.

Among the few selective agonists of group-III mGluRs, we have chosen ACPT-I to perform our experiences (Acher et al. 1997). Prior to behavioural assessment, we further examined the effect of this compound on most mGluRs. We validated that ACPT-I is indeed selective for group-III mGluRs expressed in a heterologous system, with a preference for mGlu4 over mGlu6,7,8, while presenting no agonist or antagonist activity on other mGluRs. Moreover, ACPT-I, in contrast to L- 
AP4 and other mGluR ligands (Patel et al. 2004), interacts only weakly with the transport system $\mathrm{x}_{\mathrm{c}^{-}}$. This diminishes any possible unspecific effect of ACPT-I compared to these other ligands. In agreement with this proposal, ACPT-I has already been used with success to assess the role of group III mGluRs in rodent models of Parkinson disease (Lopez et al. 2007) and anxiety and depression (Klak et al. 2007).

Our data show that intrathecally administered ACPT-I had no effect on nociceptive thresholds of healthy rats submitted to mechanical or thermal stimuli. However, following formalin injection, the nociceptive behavior of rats was significantly and dose-dependently reduced by ACPT-I in both the first and second phases associated with this pain model. These results confirm the observation by Fisher \& Coderre on the same model using L-AP4 instead of ACPT-I as a group III mGluR agonist (Fisher and Coderre 1996). The reduced behavioral score in the first phase of the formalin test suggests that group III mGluRs are present at synapses in healthy rats but, seemingly, group III mGluRs function is more likely to be revealed in conditions of severe and persistent stimulation. Consistent with that, in the different models of inflammatory and neuropathic pain, we have observed a clear reduction of hyperalgesia.

Intrathecal injection of ACPT-I also suppressed inflammatory pain in two different models with different induction periods. While inflammation of carrageenan-treated rats is effective few hours after injection, monoarthritis-induced hyperalgesia is clearly obtained in two weeks following the intra-articular injection of CFA.. Likewise, in both neuropathy models, intrathecal injection of group III agonist reduces hyperalgesia. These observations are consistent with previous results demonstrating that spinal activation of group III mGluRs by L-AP4 can decrease the development of mechanical and cold hypersensitivity associated with chronic constriction injury of the sciatic nerve in rats (Fisher et al. 2002; Chen and Pan 2005). Testing these different pain models in parallel allowed us to suggest that modulation of hyperalgesia through group III mGluRs appears like a general system, particularly efficient in the inhibition of intense, inflammatory and neuropathic hyperalgesia.

Although intrathecal injections of ACPT-I results in a very high concentration of ligands at the injection point in a short period of time, several arguments indicate that the observed effect results from group-III mGluR activation. First, the maximal effect is observed 15 to 30 minutes after the injection, when the compound is likely diluted in the injection area. Second, the effect is inhibited by both the pan-mGluR antagonist LY341495 as well as by the group-III selective antagonist MAP4. Finally, similar effects were obtained with the mGlu4 selective positive modulator PHCCC. 
It is of interest that ACPT-I and PHCCC reduces neuropathic or inflammatory hyperalgesia and not acute pain perception. Chronic pain is known to be associated with plasticity (Mogil and McCarson 2000; Woolf and Salter 2000; Pace et al. 2006). An up-regulation of the expression of group III mGluRs in sensory neurons of the pain pathway in neuropathy or inflammation could explain their lack of effect in healthy animals. However, whereas expression of group I and II mGlu receptors have been shown to be up-regulated in neuropathic or inflammatory pain models (Mills et al. 2001; Hudson et al. 2002; Mills and Hulsebosch 2002; Dolan et al. 2003), little is known about group III mGluRs. Thus, further experiments are needed to validate this hypothesis.

What could be the basis of group III mGluRs-induced attenuation of hyperalgesia? Group III mGluRs are presynaptic receptors, located close to or in the active zone of the synapse, where they induce inhibition of synaptic transmission and neurotransmitter release (except the purely retinal mGlu6) (Cartmell and Schoepp 2000). The inhibition of neurotransmitters release is mediated both by a direct inhibition of exocytosis (Chavis et al. 1998) and by an inhibition of voltage-gated $\mathrm{Ca}^{2+}$ channels (Takahashi et al. 1996; Perroy et al. 2000; Capogna 2004; Guo and Ikeda 2005). Almost all mGluRs are expressed in the spinal cord (Ohishi et al. 1995a; Ohishi et al. 1995b; Li et al. 1997; Jia et al. 1999; Azkue et al. 2001), excepting two of the four group III mGluRs: mGlu6 which is located exclusively in the retina and mGlu8 (Valerio et al. 1997; Berthele et al. 1999). Both mGlu4 and mGlu7 are present in presynaptic terminals from afferent fibers in the dorsal horn of the spinal cord (Ohishi et al. 1995a; Ohishi et al. 1995b; Li et al. 1997; Azkue et al. 2001) while mGlu8 is expressed in most DRG cell bodies (Carlton and Hargett 2007). Accordingly, electrophysiological studies have shown that group III mGluRs activation following L-AP4 infusion in dorsal horn reduces ascending informations in spinothalamic tracts resulting from mechanical noxious stimuli (Neugebauer et al. 2000). Moreover, in spinal cord slices, L-AP4 application decreases postsynaptic excitatory potentials occuring from afferent A fibers (Gerber et al. 2000). Since PHCCC produces antihyperalgesic effects similar to that of ACPT-I, the role of mGlu4 in this phenomenon is particularly emphasized. However, the involvement of mGlu7 and mGlu8 can not be ruled out and their roles remain to be elucidated.

Whatever the respective role of these receptors, the regulation of the release of glutamate they induce is certainly the main explanation for their antihyperalgesic effect. Various studies are pointing out that hyperalgesia is paralleled by an increase in the release of excitatory amino acids in the spinal cord. A transient increase of spinal glutamate and aspartate release has been observed following formalin or carrageenin injection (Sluka and Westlund 1993; Malmberg and Yaksh 1995) and in intramuscular pain model (Skyba et al. 2005). Another illustration of the importance of spinal glutamate level in nociceptive transmission is underlined by the fact that inhibiting spinal 
glutamate uptake by transporter inhibitors leads to spontaneous nociceptive behaviors and sensory hypersensitivity (Liaw et al. 2005). Moreover, peripheral neuropathy induced by spinal nerve ligation comes with alterations of spinal glutamatergic neurotransmission which contribute to allodynia and hyperalgesia. Indeed, an attenuation of glutamate transporters function is observed following spinal nerve injury and may contribute to the pathophysiology of neuropathic pain (Binns et al. 2005; Liaw et al. 2005). Thus, the importance of glutamatergic neurotransmission at the spinal cord level in the pathophysiology of maintained pain and the inhibitory role of group III mGluRs on glutamate release strongly suggest that group III mGluRs agonists or modulators act as antihyperalgesic compounds by reducing the high spinal glutamate levels associated with neuropathic or inflammatory pain.

In conclusion, the present study provides new evidences involving spinal group III mGluRs in the inhibition of hyperalgesia associated with neuropathy or inflammation. Most particularly, it highlights the specific role of mGlu4 in hyperalgesia modulation. Based on their key localization in the dorsal horn of spinal cord, on their functional roles and attenuation of behaviors observed in persistent animal pain models that have been revealed to date, group III mGluRs in general and mGlu4 in particular can be considered as promising targets for the design of novel treatments for chronic pain.

\section{ACKNOWLEDGEMENTS}

This work was supported by INSERM, the Fondation Paul Hamel, the Fédération pour la Recherche sur le Cerveau, the Agence Nationale pour la Recherche (ANR-05-NEUR-0121-04) and the Fondation de France, comité Parkinson ( $\mathrm{n}^{\circ}$ 580062). The authors also wish to thank the Plateforme Pharmacologie-Criblage of Montpellier for its technical support and the Région LanguedocRoussillon.

\section{REFERENCES}

Acher F, Tellier F, Azerad R, Brabet I, Fagni L, Pin J-P. Synthesis and pharmacological characterization of aminocyclopentane tricarboxylic acids (ACPT): new tools to 
discriminate between metabotropic glutamate receptor subtypes. J Med Chem 1997;40(19):3119-3129.

Authier N, Gillet JP, Fialip J, Eschalier A, Coudore F. A new animal model of vincristine-induced nociceptive peripheral neuropathy. Neurotoxicology 2003;24(6):797-805.

Azkue JJ, Murga M, Fernandez-Capetillo O, Mateos JM, Elezgarai I, Benitez R, Osorio A, Diez J, Puente N, Bilbao A, Bidaurrazaga A, Kuhn R, Grandes P. Immunoreactivity for the group III metabotropic glutamate receptor subtype mGluR4a in the superficial laminae of the rat spinal dorsal horn. J Comp Neurol 2001;430(4):448-457.

Bennett GJ, Xie YK. A peripheral mononeuropathy in rat that produces disorders of pain sensation like those seen in man. Pain 1988;33(1):87-107.

Berthele A, Boxall SJ, Urban A, Anneser JM, Zieglgansberger W, Urban L, Tolle TR. Distribution and developmental changes in metabotropic glutamate receptor messenger RNA expression in the rat lumbar spinal cord. Brain Res Dev Brain Res 1999;112(1):39-53.

Binns BC, Huang Y, Goettl VM, Hackshaw KV, Stephens RL, Jr. Glutamate uptake is attenuated in spinal deep dorsal and ventral horn in the rat spinal nerve ligation model. Brain Res 2005;1041(1):38-47.

Bockaert J, Pin J-P. Molecular tinkering of G-protein coupled receptors: an evolutionary success. EMBO J 1999;18(7):1723-1729.

Brabet I, Parmentier M-L, De Colle C, Bockaert J, Acher F, Pin J-P. Comparative effect of L-CCGI, DCG-IV and $\gamma$-carboxy-L-glutamate on all cloned metabotropic glutamate receptor subtypes. Neuropharmacology 1998;37:1043-1051.

Butler SH, Godefroy F, Besson JM, Weil-Fugazza J. A limited arthritic model for chronic pain studies in the rat. Pain 1992;48(1):73-81.

Capogna M. Distinct properties of presynaptic group II and III metabotropic glutamate receptormediated inhibition of perforant pathway-CA1 EPSCs. Eur J Neurosci 2004;19(10):28472858.

Carlton SM, Hargett GL. Colocalization of metabotropic glutamate receptors in rat dorsal root ganglion cells. J Comp Neurol 2007;501(5):780-789.

Cartmell J, Schoepp DD. Regulation of neurotransmitter release by metabotropic glutamate receptors. J Neurochem 2000;75(3):889-907.

Chavis P, Mollard P, Bockaert J, Manzoni O. Visualization of cyclic AMP-regulated presynaptic activity at cerebellar granule cells. Neuron 1998;20(4):773-781. 
Chen SR, Pan HL. Distinct roles of group III metabotropic glutamate receptors in control of nociception and dorsal horn neurons in normal and nerve-injured Rats. J Pharmacol Exp Ther 2005;312(1):120-126.

Dolan S, Kelly JG, Monteiro AM, Nolan AM. Up-regulation of metabotropic glutamate receptor subtypes 3 and 5 in spinal cord in a clinical model of persistent inflammation and hyperalgesia. Pain 2003;106(3):501-512.

Fisher K, Coderre TJ. The contribution of metabotropic glutamate receptors (mGluRs) to formalininduced nociception. Pain 1996;68(2-3):255-263.

Fisher K, Lefebvre C, Coderre TJ. Antinociceptive effects following intrathecal pretreatment with selective metabotropic glutamate receptor compounds in a rat model of neuropathic pain. Pharmacol Biochem Behav 2002;73(2):411-418.

Gerber G, Zhong J, Youn D, Randic M. Group II and group III metabotropic glutamate receptor agonists depress synaptic transmission in the rat spinal cord dorsal horn. Neuroscience 2000;100(2):393-406.

Gomeza J, Mary S, Brabet I, Parmentier M-L, Restituito S, Bockaert J, Pin J-P. Coupling of

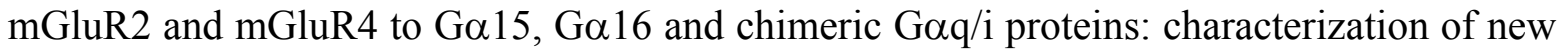
antagonists. Mol Pharmacol 1996;50:923-930.

Goudet C, Gaven F, Kniazeff J, Vol C, Liu J, Cohen-Gonsaud M, Acher F, Prezeau L, Pin JP. Heptahelical domain of metabotropic glutamate receptor 5 behaves like rhodopsin-like receptors. Proc Natl Acad Sci U S A 2004;101(1):378-383.

Guo J, Ikeda SR. Coupling of metabotropic glutamate receptor 8 to N-type Ca2+ channels in rat sympathetic neurons. Mol Pharmacol 2005;67(6):1840-1851.

Hudson LJ, Bevan S, McNair K, Gentry C, Fox A, Kuhn R, Winter J. Metabotropic glutamate receptor 5 upregulation in A-fibers after spinal nerve injury: 2-methyl-6-(phenylethynyl)pyridine (MPEP) reverses the induced thermal hyperalgesia. J Neurosci 2002;22(7):26602668.

Jia H, Rustioni A, Valtschanoff JG. Metabotropic glutamate receptors in superficial laminae of the rat dorsal horn. J Comp Neurol 1999;410(4):627-642.

Klak K, Palucha A, Branski P, Sowa M, Pilc A. Combined administration of PHCCC, a positive allosteric modulator of mGlu4 receptors and ACPT-I, mGlu III receptor agonist evokes antidepressant-like effects in rats. Amino Acids 2007;32(2):169-172.

Konieczny J, Wardas J, Kuter K, Pilc A, Ossowska K. The influence of group III metabotropic glutamate receptor stimulation by $(1 \mathrm{~S}, 3 \mathrm{R}, 4 \mathrm{~S})-1$-aminocyclo-pentane-1,3,4-tricarboxylic acid 
on the parkinsonian-like akinesia and striatal proenkephalin and prodynorphin mRNA expression in rats. Neuroscience 2007;145(2):611-620.

Li H, Ohishi H, Kinoshita A, Shigemoto R, Nomura S, Mizuno N. Localization of a metabotropic glutamate receptor, mGluR7, in axon terminals of presumed nociceptive, primary afferent fibers in the superficial layers of the spinal dorsal horn: an electron microscope study in the rat. Neurosci Lett 1997;223(3):153-156.

Liaw WJ, Stephens RL, Jr., Binns BC, Chu Y, Sepkuty JP, Johns RA, Rothstein JD, Tao YX. Spinal glutamate uptake is critical for maintaining normal sensory transmission in rat spinal cord. Pain 2005;115(1-2):60-70.

Lopez S, Turle-Lorenzo N, Acher F, De Leonibus E, Mele A, Amalric M. Targeting group III metabotropic glutamate receptors produces complex behavioral effects in rodent models of Parkinson's disease. J Neurosci 2007;27(25):6701-6711.

Madden DR. The structure and function of glutamate receptor ion channels. Nat Rev Neurosci 2002;3(2):91-101.

Maj M, Bruno V, Dragic Z, Yamamoto R, Battaglia G, Inderbitzin W, Stoehr N, Stein T, Gasparini F, Vranesic I, Kuhn R, Nicoletti F, Flor PJ. (-)-PHCCC, a positive allosteric modulator of mGluR4: characterization, mechanism of action, and neuroprotection. Neuropharmacology 2003;45(7):895-906.

Malmberg AB, Yaksh TL. Cyclooxygenase inhibition and the spinal release of prostaglandin E2 and amino acids evoked by paw formalin injection: a microdialysis study in unanesthetized rats. J Neurosci 1995;15(4):2768-2776.

Marino MJ, Williams DL, Jr., O'Brien JA, Valenti O, McDonald TP, Clements MK, Wang R, DiLella AG, Hess JF, Kinney GG, Conn PJ. Allosteric modulation of group III metabotropic glutamate receptor 4: a potential approach to Parkinson's disease treatment. Proc Natl Acad Sci U S A 2003;100(23):13668-13673.

Mestre C, Pelissier T, Fialip J, Wilcox G, Eschalier A. A method to perform direct transcutaneous intrathecal injection in rats. J Pharmacol Toxicol Methods 1994;32(4):197-200.

Mills CD, Fullwood SD, Hulsebosch CE. Changes in metabotropic glutamate receptor expression following spinal cord injury. Exp Neurol 2001;170(2):244-257.

Mills CD, Hulsebosch CE. Increased expression of metabotropic glutamate receptor subtype 1 on spinothalamic tract neurons following spinal cord injury in the rat. Neurosci Lett 2002;319(2):59-62.

Mogil JS, McCarson KE. Identifying pain genes: bottom-up and top-down approaches. J Pain 2000;1(3 Suppl):66-80. 
Neugebauer V. Peripheral metabotropic glutamate receptors: fight the pain where it hurts. Trends Neurosci 2001;24(10):550-552.

Neugebauer V. Metabotropic glutamate receptors--important modulators of nociception and pain behavior. Pain 2002;98(1-2):1-8.

Neugebauer V. Glutamate receptor ligands. Handb Exp Pharmacol 2007(177):217-249.

Neugebauer V, Chen PS, Willis WD. Groups II and III metabotropic glutamate receptors differentially modulate brief and prolonged nociception in primate STT cells. J Neurophysiol 2000;84(6):2998-3009.

Ohishi H, Akazawa C, Shigemoto R, Nakanishi S, Mizuno N. Distributions of the mRNAs for L-2amino-4-phosphonobutyrate-sensitive metabotropic glutamate receptors, mGluR4 and mGluR7, in the rat brain. J Comp Neurol 1995a;360(4):555-570.

Ohishi H, Nomura S, Ding YQ, Shigemoto R, Wada E, Kinoshita A, Li JL, Neki A, Nakanishi S, Mizuno N. Presynaptic localization of a metabotropic glutamate receptor, mGluR7, in the primary afferent neurons: an immunohistochemical study in the rat. Neurosci Lett 1995b;202(1-2):85-88.

Oyama T, Ueda M, Kuraishi Y, Akaike A, Satoh M. Dual effect of serotonin on formalin-induced nociception in the rat spinal cord. Neurosci Res 1996;25(2):129-135.

Pace MC, Mazzariello L, Passavanti MB, Sansone P, Barbarisi M, Aurilio C. Neurobiology of pain. J Cell Physiol 2006;209(1):8-12.

Patel SA, Warren BA, Rhoderick JF, Bridges RJ. Differentiation of substrate and non-substrate inhibitors of transport system xc(-): an obligate exchanger of L-glutamate and L-cystine. Neuropharmacology 2004;46(2):273-284.

Perroy J, Prezeau L, De Waard M, Shigemoto R, Bockaert J, Fagni L. Selective blockade of P/Qtype calcium channels by the metabotropic glutamate receptor type 7 involves a phospholipase C pathway in neurons. J Neurosci 2000;20(21):7896-7904.

Pin J-P, Acher F. The metabotropic glutamate receptors: structure, activation mechanism and pharmacology. Cur Drug Targets - CNS \& Neur Dis 2002;1:297-317.

Pin JP, Bockaert J, Recasesn M. The Ca2+/C1- dependent L-[3H]glutamate binding: a new receptor or a particular transport process? FEBS Lett 1984;175(1):31-36.

Pin JP, Kniazeff J, Liu J, Binet V, Goudet C, Rondard P, Prezeau L. Allosteric functioning of dimeric class C G-protein-coupled receptors. Febs J 2005;272(12):2947-2955.

Skyba DA, Lisi TL, Sluka KA. Excitatory amino acid concentrations increase in the spinal cord dorsal horn after repeated intramuscular injection of acidic saline. Pain 2005;119(1-3):142149. 
Sluka KA, Westlund KN. Spinal cord amino acid release and content in an arthritis model: the effects of pretreatment with non-NMDA, NMDA, and NK1 receptor antagonists. Brain Res 1993;627(1):89-103.

Takahashi T, Forsythe ID, Tsujimoto T, Barnes-Davies M, Onodera K. Presynaptic calcium current modulation by a metabotropic glutamate receptor. Science 1996;274(5287):594-597.

Valerio A, Paterlini M, Boifava M, Memo M, Spano P. Metabotropic glutamate receptor mRNA expression in rat spinal cord. Neuroreport 1997;8(12):2695-2699.

Varney M, Gereau RW. Metabotropic glutamate receptor involvement in models of acute and persistent pain: prospect for the development of novel analgesics. Cur Drug Targets: CNS and Neur Dis 2002;1(3):283-296.

Wheeler-Aceto H, Porreca F, Cowan A. The rat paw formalin test: comparison of noxious agents. Pain 1990;40(2):229-238.

Woolf CJ, Salter MW. Neuronal plasticity: increasing the gain in pain. Science 2000;288(5472):1765-1769.

Zimmermann M. Ethical guidelines for investigations of experimental pain in conscious animals. Pain 1983;16(2):109-110. 


\section{FIGURE LEGENDS}

Figure 1. ACPT-I is a selective group-III mGluRs agonist.

A. Dose-response curves of ACPT-I on the different group III mGluRs. B. Lack of agonist activity of ACPT-I $(100 \mu \mathrm{M})$ on group I and group II mGluRs. While ACPT-I dose-dependently activates group-III mGluRs, even at high concentration ACPT-I fails to induce activity of group-I and -II mGluRs. Receptor activity is determined by the accumulation of IP following the stimulation by various concentrations of ACPT-I for group-III mGluRs and at a fixed concentration of $100 \mu \mathrm{M}$ for group-I and -II mGluRs. The results are expressed as the percentage of the maximal activity induced by ACPT-I, each point corresponding to the mean \pm S.E.M. of triplicate. Data presented are representative of $n=3$ at least experiments. C. Interaction of ACPT-I with L-Glutamate uptake through $\mathrm{x}_{\mathrm{c}^{-}}$transport system into rat brain membranes. Inhibition of chloride dependent $\mathrm{L}-{ }^{3} \mathrm{H}-$ Glutamate $(100 \mathrm{nM})$ uptake by ACPT-I or L-AP4 was measured into rat brain membranes in 50mM Tris-citrate buffer (pH7.4) in presence of $2.5 \mathrm{mM} \mathrm{CaCl}_{2}$. Values are $\%$ of control (mean \pm S.E.M. of 3 independent experiments) and are corrected for non-specific uptake.

Figure 2. Effect of intrathecal administration of ACPT-I on pain evoked by mechanical, thermal or chemical stimuli in healthy animals.

A. Effect of ACPT-I (20, 40, $80 \mu \mathrm{g} / \mathrm{rat}$, i.t.) on time-course of vocalization threshold to paw pressure. Morphine (10 $\mu \mathrm{g} / \mathrm{rat}$, i.t.) is used as a positive control. Results are expressed by the timecourse curves of means \pm S.E.M. of vocalization threshold in grams ( $n=7-8$ rats per group). B. Effect of ACPT-I on tail immersion time in hot water $\left(46^{\circ} \mathrm{C}\right)$. Morphine $(10 \mu \mathrm{g} / \mathrm{rat}$, i.t. $)$ is used as a positive control. Results are expressed by the time-course of means \pm S.E.M. of the latency of tail withdrawal in seconds ( $\mathrm{n}=7-8$ rats per group). C. Effect of ACPT-I $(2,10,20,40,80 \mu \mathrm{g} / \mathrm{rat}$, i.t.) on nociceptive scores following formalin injection in rat hind paw. Morphine (10 $\mu \mathrm{g} / \mathrm{rat}$, i.t.) is used as a positive control. The results are expressed as mean \pm S.E.M. of the cumulative biting and licking time during each phase ( $\mathrm{n}=6$ per group).

Figure 3. Effect of intrathecal administration of ACPT-I on the vocalization threshold to paw pressure in inflammatory pain models: carrageenin-treated rats (A) and monoarthritic rats (B).

Results are expressed by the time-course curves of mean \pm S.E.M. of vocalisation thresholds $(\mathrm{g})$ in the left panel and by the area under curve in the right panel. Rats were treated with either vehicle, ACPT-I $(2,10,20,40,80 \mu \mathrm{g} /$ rat, i.t. $)$ or morphine $(10 \mu \mathrm{g} / \mathrm{rat})(\mathrm{n}=7-8$ per group $)$ administrated 240 
min after intraplantar injection of carrageenin or two weeks after intra-articular injection of complete Freund's adjuvant into the tibio-tarsal joint. * $\mathrm{P}<0.05$ vs. vehicle-treated group.

Figure 4. Effect of intrathecal administration of ACPT-I on the vocalization threshold to paw pressure in neuropathic pain models: mononeuropathic rats $(A)$ and vincristine-treated rats (B). Results are expressed by the time-course curves of means \pm S.E.M. of vocalization threshold (expressed in grams) in the left panel and by the area under curve (AUC, g.min) in the right panel. Two weeks after sciatic nerve ligature or following the first administration of vincristine, rats were treated either with saline or ACPT-I (from 2 to $80 \mu \mathrm{g} /$ rat, i.t.)(n=7-8 rats per group). $* \mathrm{P}<0.05$ vs. vehicle-treated group.

Figure 5. Block of ACPT-I effect by group III-selective and non-selective mGluRs antagonists in inflammatory or neuropathic pain models.

Time-course of the effect of the non-selective mGluRs antagonist LY341495 versus ACPT-I in carrageenin-treated rats B. Time-course of the effect of the selective group-III mGluRs antagonist MAP4 versus ACPT-I in carrageenin-treated rats. C. Time-course of the effect of the selective group-III mGluRs antagonist MAP4 versus ACPT-I in mononeuropathic rats. Results represented correspond to the time-course curves of mean \pm S.E.M. of vocalisation thresholds $(\mathrm{g})$ in the left panel and the corresponding area under curve (AUC, g.min) in the right panel. Rats were treated either with vehicle plus vehicle, ACPT-I $(80 \mu \mathrm{g} / \mathrm{rat}$, i.t.) plus vehicle, ACPT-I $(80 \mu \mathrm{g} / \mathrm{rat})$ plus MAP4 (from 25 to $100 \mu \mathrm{g} / \mathrm{rat}$, as stated) or ACPT-I (80 $\mu \mathrm{g} / \mathrm{rat}$ ) plus LY341495 (from 62.5 to 250 $\mu \mathrm{g} / \mathrm{rat}$, as stated) ( $\mathrm{n}=7-8$ per group) administrated $240 \mathrm{~min}$ after intraplantar injection of carrageenin or two weeks after ligature of sciatic nerve. ${ }^{*} \mathrm{P}<0.05$ vs. vehicle-treated group.

Figure 6. Effect of intrathecal administration of mGlu4 positive allosteric modulator PHCCC on the vocalization threshold to paw pressure in healthy rats (A), inflammatory (carrageenintreated rats, B) or neuropathic pain models (mononeuropathic rats, $C$ ).

Results are expressed by the time-course curves of means \pm S.E.M. of vocalization threshold (expressed in grams) in the left panel and by the area under curve (AUC, g.min) in the right panel. Rats were treated either with vehicle, PHCCC (various doses as indicated in $\mu \mathrm{g} / \mathrm{rat}$, i.t.) or morphine $(10 \mu \mathrm{g} / \mathrm{rat}$, i.t.) administrated $240 \mathrm{~min}$ after intraplantar injection of carrageenin or two weeks after ligature of sciatic nerve ( $\mathrm{n}=7-8$ per group). $* \mathrm{P}<0.05$ vs. vehicle-treated group. 
A

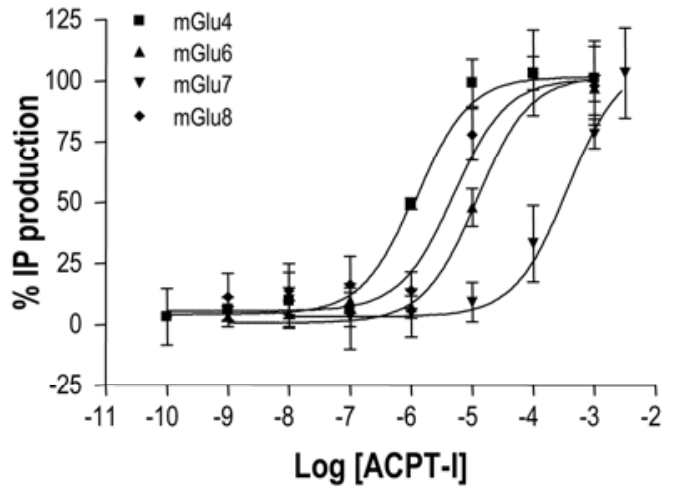

B

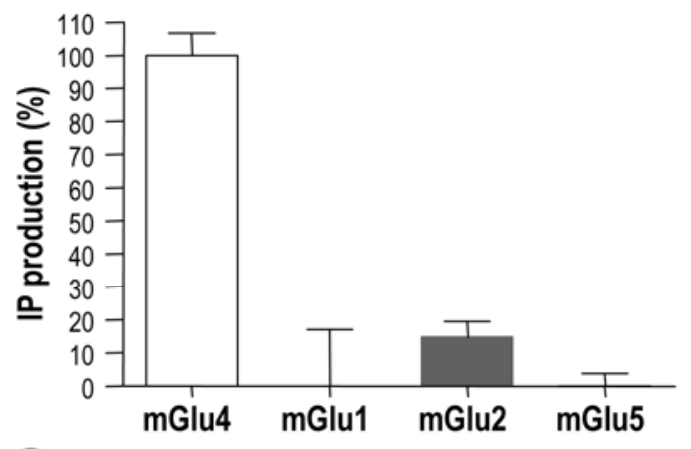

C $_{120}$

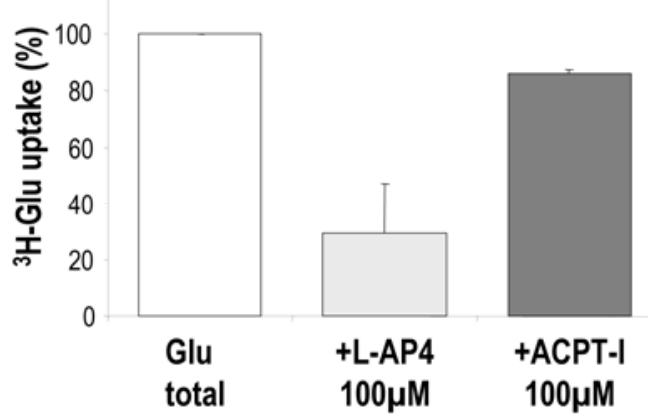

Figure 1 


\section{A - Mechanical stimulus}

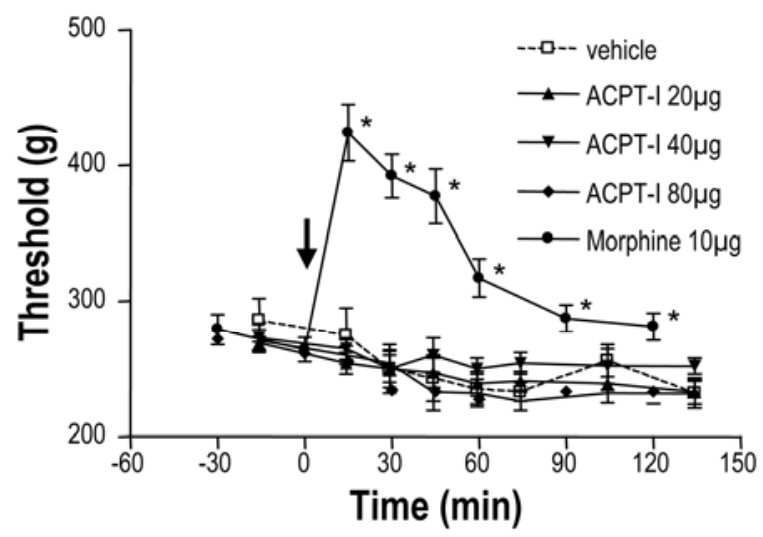

\section{B - Thermal stimulus}

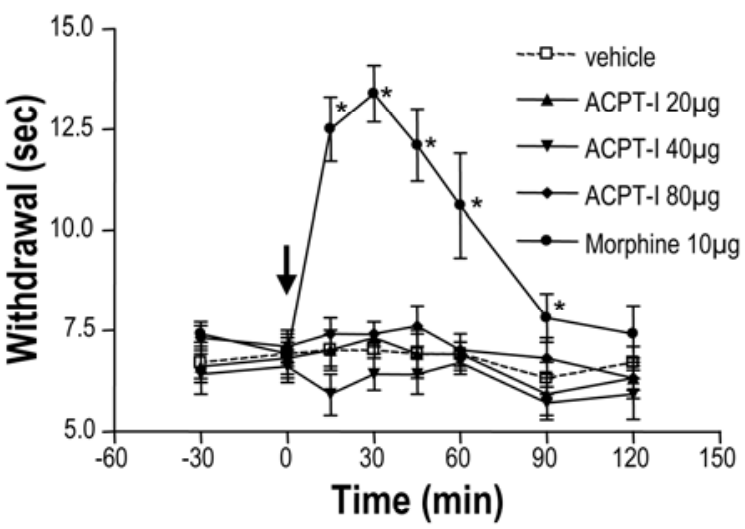

\section{C - Chemical stimulus}

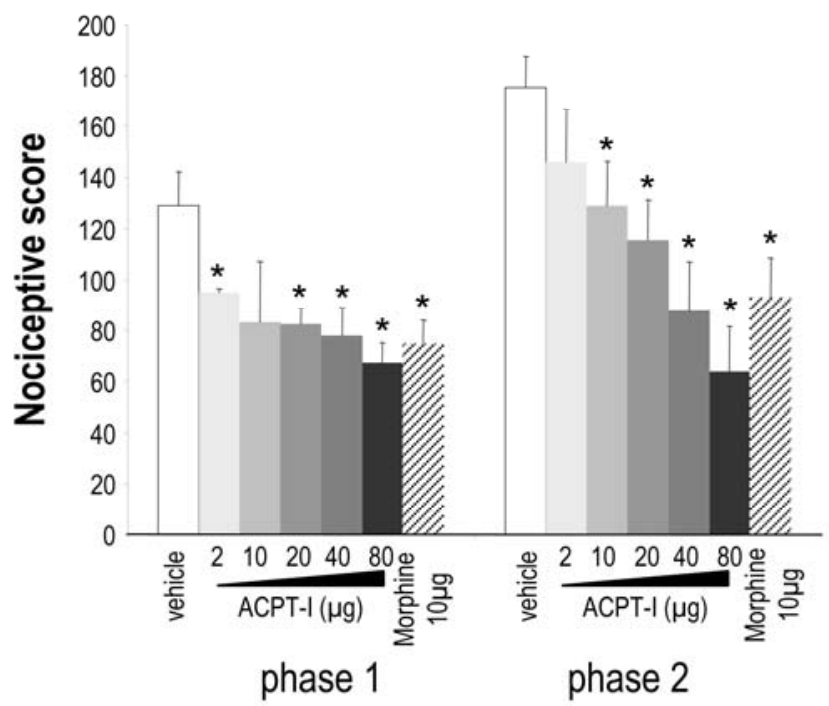

Figure 2 


\section{A - Carrageenan}
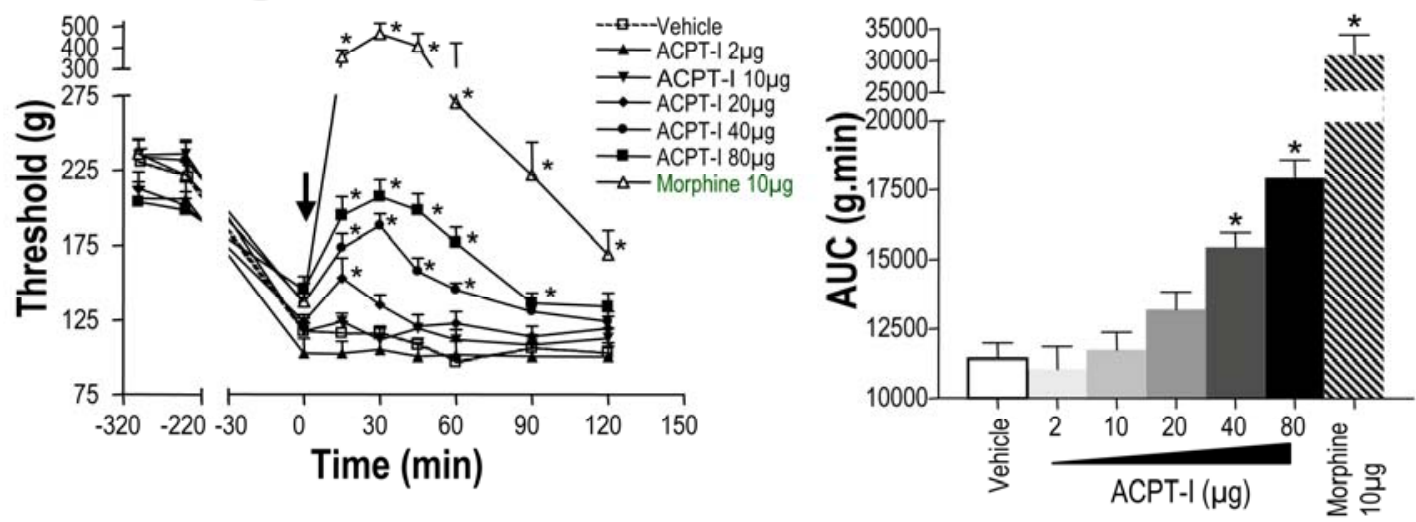

\section{B - Monoarthritic}
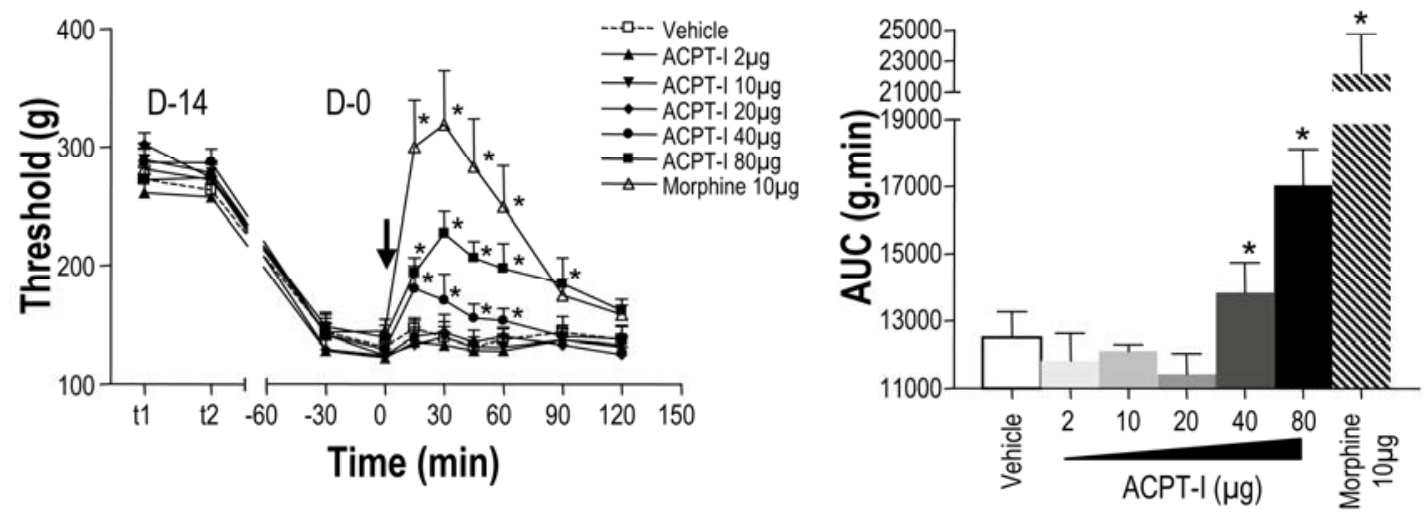

Figure 3 


\section{A - Chronic constriction injury}

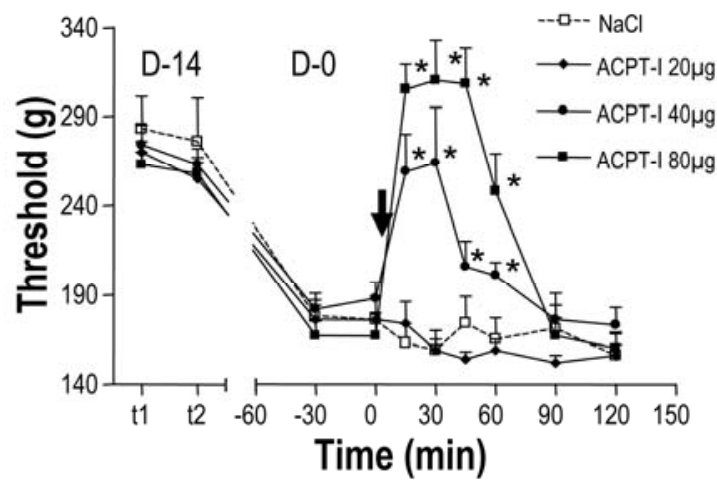

\section{B - Vincristine}
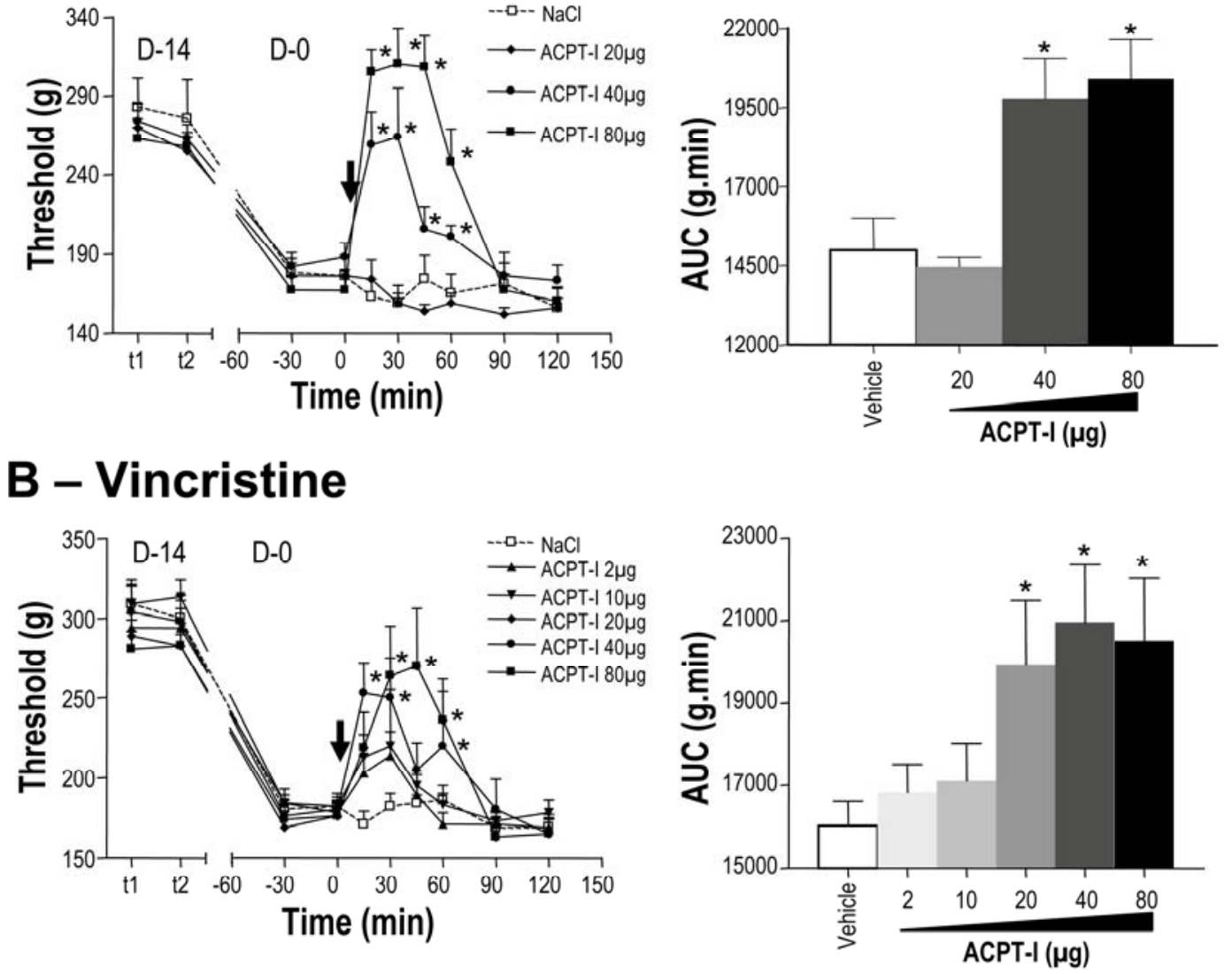

Figure 4 


\section{A - Carrageenan}
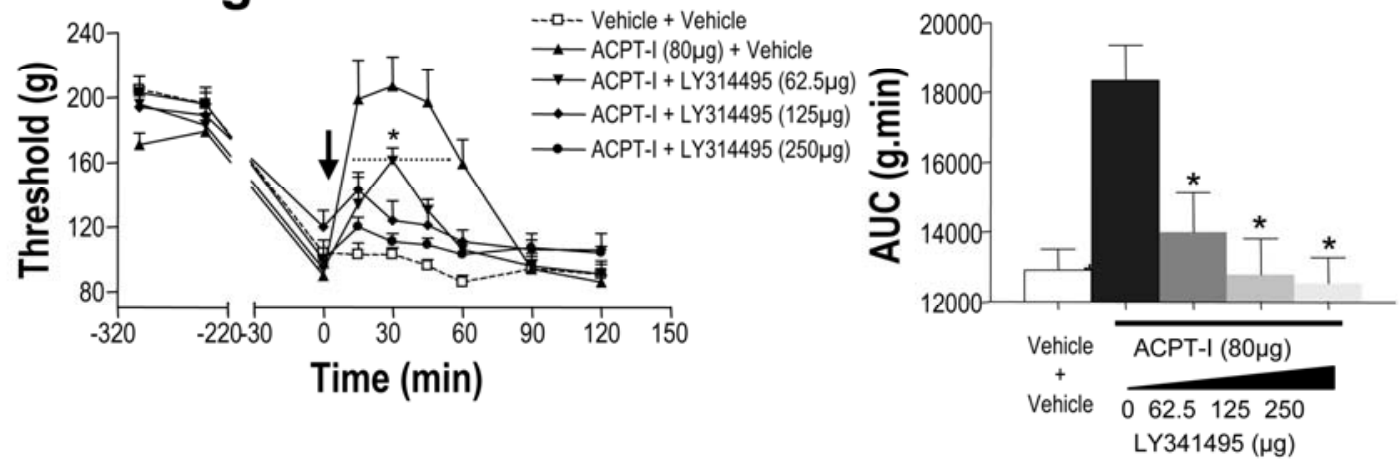

\section{B - Carrageenan}
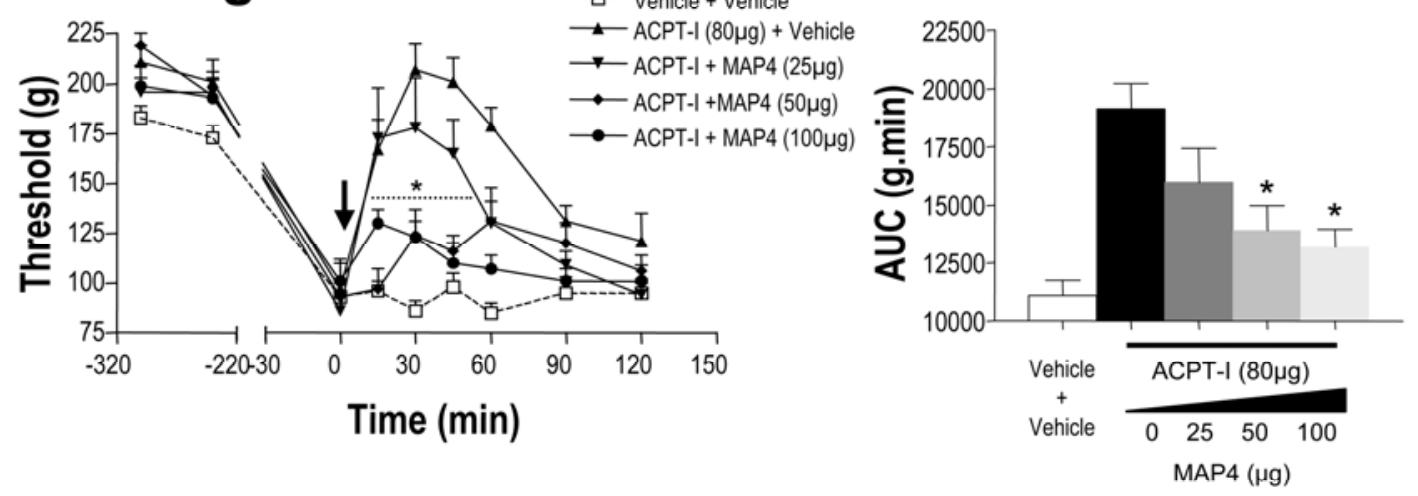

\section{C - CCl}

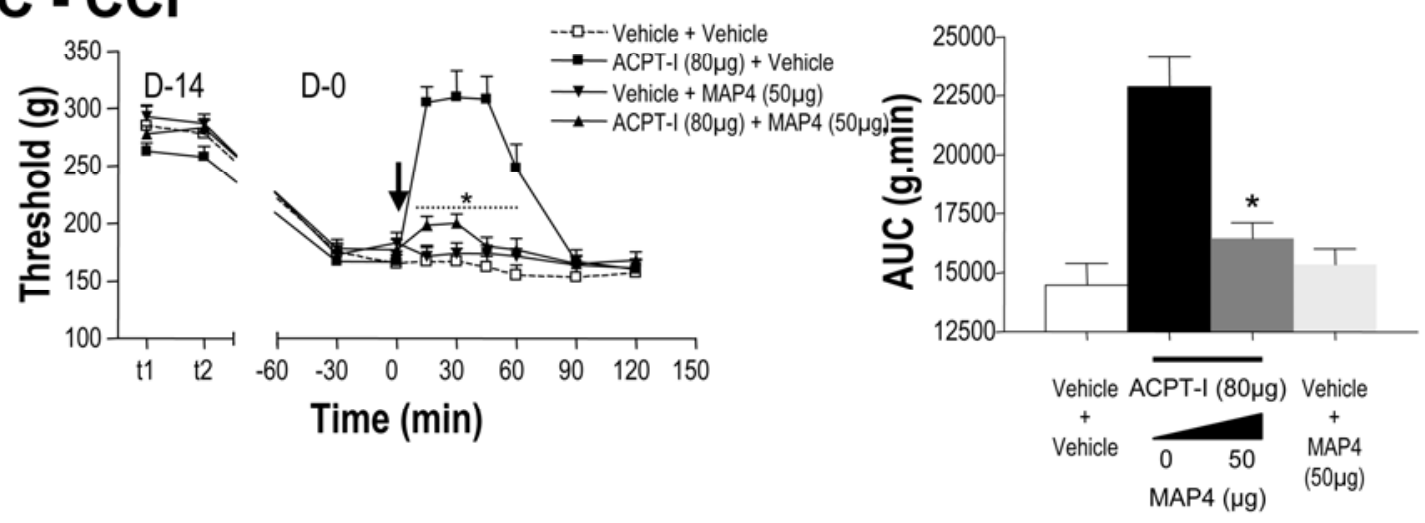

Figure 5 


\section{A. Healthy rats}
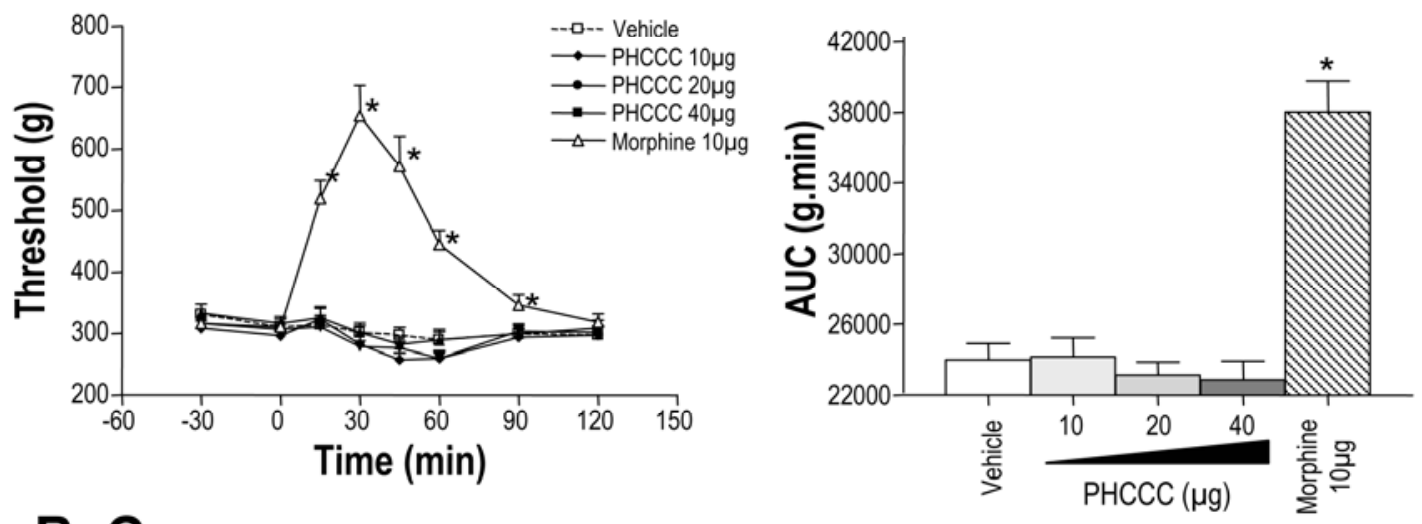

\section{B. Carrageenan}
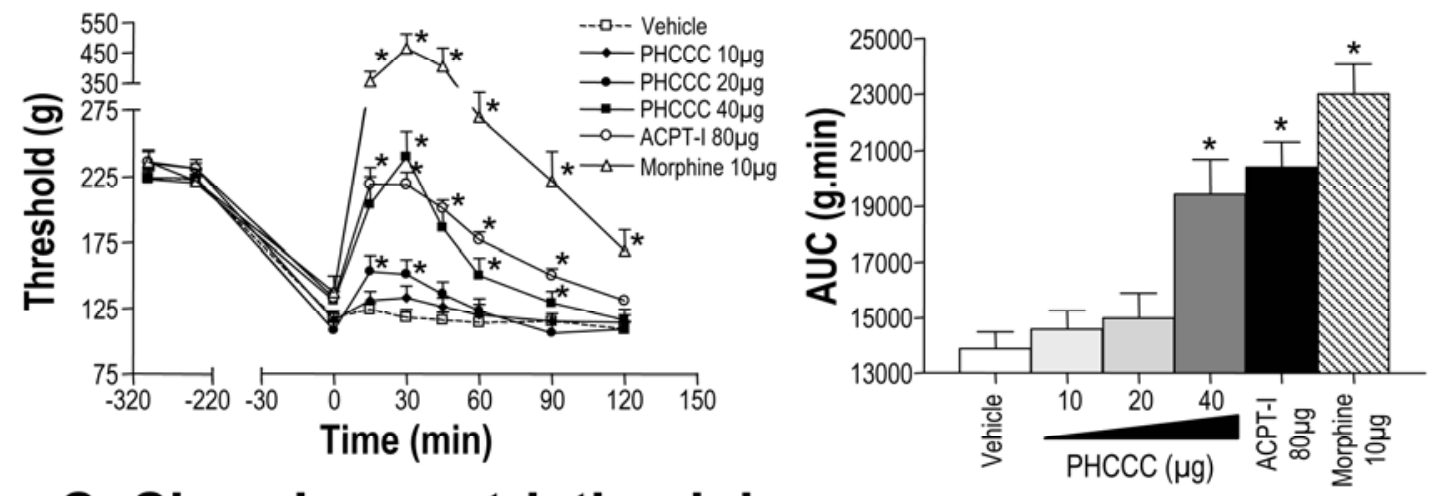

\section{Chronic constriction injury}
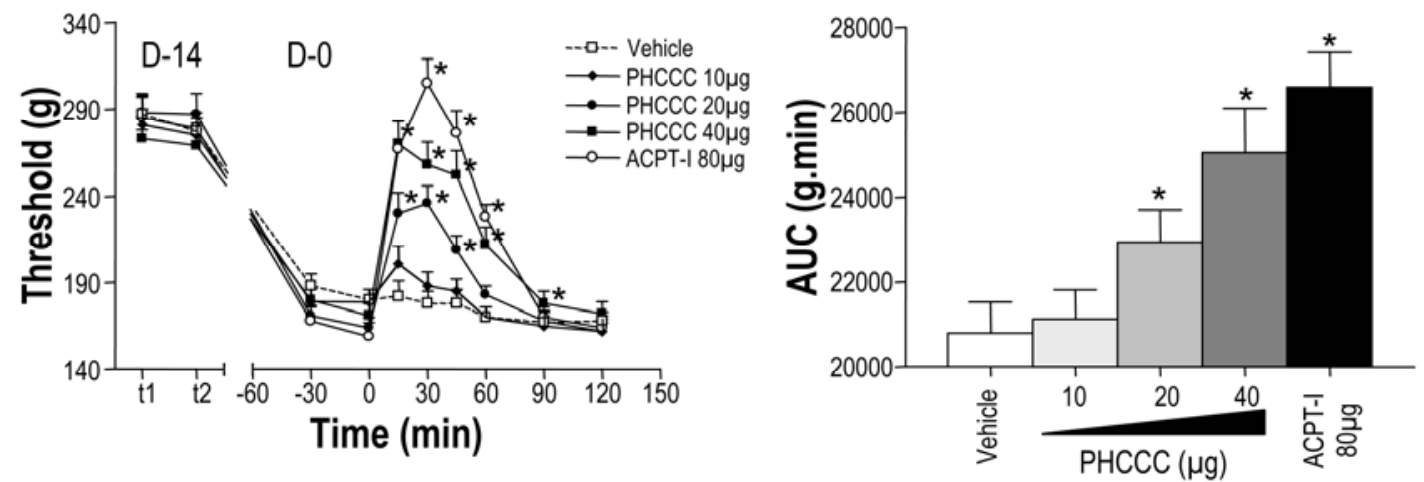

Figure 6 